\title{
Review of the Research on the Clean System of Chinese Universities
}

\author{
Gaohe Wang \\ Marxism Studies of Jinan University \\ Guangzhou, Guangdong, China 510632
}

\begin{abstract}
At present, the research on anti-corruption system of Chinese universities conducted by the theoretical circle basically follows the normal form and thinking that combines punishment and prevention. They hold the opinion that the establishment and improvement of organization mechanism, educational mechanism, responsibilities mechanism, restriction mechanism, supervisory mechanism and punishment mechanism of anti-corruption in universities are the top priorities of the construction of a clean and honest administration of universities.
\end{abstract}

Keywords-universities; clean system; research review

\section{INTRODUCTION}

In recent years, the corruption phenomenon in universities spreads unceasingly. The quantity of people, the amount of money and the rank of leading cadres involved in the case are unprecedented. Accordingly, the theoretical circle intensifies the research on the construction of a clean and honest administration of universities. Related research achievements come out. In the researches on the construction of a clean and honest administration of universities, the anti-corruption system construction is the top priority. From the perspective of the present main achievements, the research on the anticorruption system of universities conducted by the theoretical circle has made great progress, but it still needs further expansion and deepening.

\section{NORMAL FORM AND THINKING OF THE EXISTING RESEARCH}

At present, although domestic scholars engaged in the research on the construction of a clean and honest administration of universities come from multiple disciplines, such as pedagogy, politics and law, the analyses on anticorruption system in universities basically follow the same or similar thinking, namely research on how to build anticorruption system of universities from two points of view: "punishment" and "prevention". Differences in researches among scholars mainly embody in the perspective of demonstration.

Some scholars analyze from the comprehensive perspective of punishment and prevention. For example, Ouyang Yuan thinks universities should carry out mechanism and system innovation to establish and improve cohesive, matched and

Fund project: This article is the staged achievement of the national social science fund youth project "Research on Comprehensively Deepening Reform of the Problem of Seeking the Greatest Common Divisor of Public Opinion in Practice and Its Solution" (Project No.: 15CKS20). Host: Wang Gaohe. effective education, system and supervision and restriction system and specific system to build the system to punish and prevent corruption[1]; Chen Libin puts forward that in order to establish and improve the system to punish and prevent corruption in universities, we should base on the education to build ideological basis for the system and supervision, use the system to provide guarantee for education and supervision and use supervision to promote the implementation of education and system, meanwhile, use accountability system to promote the actual effect of education, system and supervision [2]; $\mathrm{Li}$ Zhengwu believes we should establish and improve the education of clean politics, institutional prevention and control, power operation, punishment and responsibility investigation, leadership system and working mechanism of universities [3]. Some scholars analyze from one perspective of punishment and prevention. For example, Huang Feiyan discusses anticorruption system of universities from the perspective of education to build moral defense [4]; Wang Shuqin analyzes the methods of the construction of a clean and honest administration of universities from the perspective of supervision and restriction to establish and improve the restriction mechanism of power operation in universities [5]; Gan Guiyang demonstrates the path of the construction of a clean and honest administration of universities from the perspective of risk prevention and control to build the risk prevention management system of "early warning in earlier stage, prevention and control in medium term, assessment and correction in later period" [6].

\section{MAIN PROBLEMS EXISTING IN ANTI-CORRUPTION SYSTEM OF CHINESE UNIVERSITIES}

The system is fundamental, integral, stable and long-term. In anti-corruption construction of universities, we should put the system construction in the prominent position and let the system run through all links of the anti-corruption construction of universities. At present, the theoretical circle widely believes there are many problems existing in the anticorruption system of Chinese universities.

\section{A. The System Design Is not Dynamic Enough}

Chen Xiaobin thinks as work procedure and operative norm followed by people, the system stands the test of development and change. With continuous development and change of the situation, the system formulated in the past more or less exposes imperfect, inadaptable and unscientific design. 
Therefore, the system design must keep pace with the times and keep dynamic. However, from the perspective of anticorruption system construction of our country, the system design is relatively static and lagging to some extent. Many systems have been used since the 1980s and have remained unchanged till now. It influences the implementation effect of systems. [7] $\mathrm{Gu}$ Zhaoming says the corruption behavior is changing all the time, but the anti-corruption system of universities cannot carry out dynamic adjustment in time. It cannot make quick response to corruption behavior nor prevent effectively, lacking foresight. [8] Jiang Guoying thinks in recent years, the career of Chinese universities develops very fast, but the anti-corruption system of universities still sticks to the outdated experience, views and systems and does not insist on emancipating the mind and seeking truth from facts, keeping pace with the times. It cannot adapt to actual state of the school and the needs of career development, which give opportunity for some lawbreakers to exploit an advantage. [9]

\section{B. The System Is Unsound}

Having "system" to follow is the basic safeguard for the anti-corruption construction of universities to achieve good results. Compared with new situation and new task, the anticorruption system of Chinese universities is unsound. For example, Xiao Zheng thinks the anti-corruption construction of universities should extend to every aspect of the school work. At present, the anti-corruption system formulated by some universities mainly involves the management of people, finance and objects and pays inadequate attention to teaching management, non-academic education, subject setting, scientific research and development. The system construction is not comprehensive. [10] Liang Aiwen thinks the Opinion on Strengthening Anti-corruption Construction of Universities stipulates that universities should improve scientific and democratic policy-making mechanism of the leading group, enhance the management and supervision of the leading cadres and the personnel management and supervision of the cadres, internal financial management and supervision, the management and supervision of infrastructure project, as well as the university enterprise and national assets. Judging from the above requirements, there are many system vacancies and problems needing further improvement in the existing anticorruption system of universities. [11]

\section{The System Is not Systematic}

A perfect institutional system must be coherent and carry out self operation, self-adjustment and overall linkage as well as front and back closure. The more integral and systematic of the institutional system, the more rigorous the system will be and the more effective the execution will be. At present, the anti-corruption system of Chinese universities is not systematic enough. For example, Tang Huasheng thinks although Chinese universities have established many anti-corruption systems, they lack organic connection and are not systematic. Just like high quality parts that are not assembled into a complete machine, so it is difficult to take due effect in practice. So to speak, in the anti-corruption system construction, most universities attach importance to inner-party system construction and neglect the system arrangement at the levels of the country and the society. It hasn't formed the institutional chain that the inner-party anti-corruption and anti-corruption outside the Party complement, coordinate and link with each other. [12] Gu Zhaoming argues that the anti-corruption system construction of Chinese universities is not systematic enough and it mainly shows in three aspects: Firstly, universities pay attention to single system construction and neglect the construction of systematic institutional networks in the anti-corruption system construction. Secondly, universities pay attention to substantive system construction and neglect procedural system construction in the anti-corruption system construction. Thirdly, in the anti-corruption system construction, universities pay attention to the system construction that restrains corruption and neglect the system construction that implements the system. It lacks implementation system and accountability system matched with related systems, which objectively weaken the power of these systems. [13]

\section{The System Is not Rigid Enough}

Even though a system is perfect, if it cannot be implemented, it is difficult to embody its value. Sun Yinghou thinks there are too many interference factors in the implementation of anti-corruption system. The requirements of system should be rigid without discount, but in the specific implementation process, because of the interference of relatives, friends and colleagues, the system contents are misinterpreted on purpose or implemented improperly. The implementation effect of system is satisfactory. [14] Hong Niansheng thinks it mainly has two reasons: Firstly, a few leading cadres are not aware of the importance of implementing the anti-corruption system inwardly and are inclined to pay attention to the formulation of systems and attach less importance to the implementation of systems. Secondly, some functional departments of universities start from the departmental benefits. They implement if the system is good for them and do not implement if it is not beneficial, so that the system implementation is random. The specific personnel also exploit an advantage. Therefore, the implementation of system with certain alterations often appears. It seriously influences the credibility and authority of the system. [15]

\section{ESTABLISH ANTI-CORRUPTION SYSTEM OF CHINESE UNIVERSITIES}

From the perspective of the existing research achievements, the establishment of anti-corruption system of Chinese universities should proceed with organization mechanism, responsibility mechanism, restriction mechanism, supervision mechanism and punishment mechanism.

\section{A. Organization Mechanism}

The organizational leadership is the core to combat corruption and uphold integrity. Universities should base on requirements of the central committee and build centralized leadership of the Party committee. The Party and the government make concerted efforts. The discipline inspection commission organizes and coordinates. Departments perform their own functions and rely on the anti-corruption leadership mechanism and working mechanism that the masses support 
and participate in. Firstly, the Party committee of the school should take the anti-corruption construction as important political task and implement it and list it in important agenda and integrate it in central tasks to realize normal and systematic anti-corruption construction. [16] Secondly, specially set up the leading group of anti-corruption system construction and implementation with main leaders of the school as group leaders, other leaders as vice directors of the group, departments such as the Office of the Party Committee, the president's office, discipline inspection, supervision, publicity, organization, personnel and audit as members, to regularly research anti-corruption construction and system construction, ceaselessly improve the quality of anti-corruption system, form concerted efforts to implement the system and guarantee the effective implementation of anti-corruption system. [17] Thirdly, establish and improve the responsibility system of the clean and honest government including resolution of responsibilities, responsibility assessment and responsibility investigation. Through the establishment and implementation of responsibility system of incorrupt government, strive to form a systematic responsibility network of combating corruption and upholding integrity and ensure the anti-corruption work of universities implements and gets result on organizational leadership. [18]

\section{B. Educational Mechanism}

The establishment and improvement of educational mechanism of incorrupt government is to build the first line of defense that leading cadres of Party members of universities repeal the corrupting influence. Universities should prevent and control corruption from the source, put the ideological education in an important place and consolidate this basis as well as spare no effort to solve problems existing in Party spirit, Party style and Party discipline. Firstly, strengthen organizational education and improve the mechanism of organizational education. First, insist on the system that the central group should regularly learn the theory of combating corruption and upholding integrity. Second, insist on and improve the system that the leading cadres of the party and the government regularly teach Party class of anti-corruption or give a speech related to combating corruption and upholding integrity. Third, insist on and improve the system of incorrupt government conversation and regular analysis of Party spirit. Four, insist on and improve incorrupt government training and examination system. Five, insist on and improve exemplary education, warning education, theme education and the post education system. [19] Secondly, strengthen self-education and establish and improve self-discipline mechanism. The elimination of corruption rests on the political and moral quality of people, because people execute power, accept supervision and regulate desire all by themselves. Now at the important period of combating corruption and upholding integrity, universities must support the healthy energy and raise the noble spirit. Leading cadres of universities must insist on using the Marxism to arm the mind, establish sound understanding of power, view of interest and outlook for honor and disgrace and strengthen the communist ideal and belief, train the communist moral cultivation, build noble ideological and mental state, and vigorously advocate the good ethos of being honest and diligent, building a party serving the interests of the people and dedication and improve comprehensive quality and ability of repealing the corruption influence, at the meantime, fundamentally build the foundation of combating corruption and upholding integrity. [20] Thirdly, strengthen family education. Many examples in life tell us the fortress of corruption is often broken from the inner side of the family. It is difficult for a person to be uncorrupted if his family members are corrupt. Family education also plays a crucial role in combating corruption and upholding integrity. Therefore, it is necessary to strengthen the education on spouse, children and other relatives of leading cadres of universities and let them help, promote and insist on the integrity and create good family environment for anti-corruption construction of universities. [21] Fourthly, strengthen social education and create the cultural atmosphere of integrity. Take various forms, strengthen the education of clean politics for the whole society, build the clean governance culture and form profound atmosphere of being proud of integrity and being shamed of corruption, meanwhile, create good social environment for anti-corruption construction of universities. [22]

\section{Responsibility Mechanism}

To ensure the integral implementation of the system, it is necessary to establish responsibility mechanism that rights and liabilities are strictly consistent. Firstly, practice the principle of "one who takes charge should be responsible" and establish accountability system of fault appearing in anti-corruption work of leading cadres of universities. If knowing serious discipline violations and violation of laws of staff and ignoring it, causing baneful influence or neglecting managerial supervision, leaders who take charge should shoulder the responsibility in accordance with the law and procedures. [23] Secondly, realize rigid and normative accountability system through formulating and improving related laws. Let leading cadres and ordinary staff of universities clearly understand the accountability condition, accountability process and accountability results, and then consciously restrict their behavior and safeguard rights and interests of their won. The accountability system of combating corruption and upholding integrity can set standard of behavior for leading cadres to administrate and provide guarantee for staff of universities to supervise effectively and provide basis for authorities to ascertain where the responsibility lies. [24] Thirdly, enrich means of accountability. Implement the accountability through various means of responsibility investigation such as criticism and education, admonishing conversation, organizational sanction and administrative penalty to ensure the implementation of responsibility investigation. [25]

\section{Restriction Mechanism}

Practice has proved that the power without restriction will inevitably lead to corruption. Therefore, it is necessary to form operation mechanism of power of universities with reasonable structure, scientific allocation, strict procedure and effective restriction through system construction and ensure the power operates in the sun. Firstly, establish the democratic decisionmaking system of leading group. Universities should base on the democratic centralism and implement the system of division of responsibility of the leading group, establish and 
improve the decision rule of discussing official business and decision-making process. All decision-making of bug issues, appointment and dismissal of important leading cadres and important project arrangement should be submitted to the meeting of school leaders or the standing committee of the Party committee to discuss. The leading group of the party and government administration decides together. [26] In financial management, universities should strengthen the restriction of the right of property. Schools and departments should change "one pen" into "top leaders". Leaders of departments and responsible person jointly check on the shared signature system of "many pens", or it cannot claim payment. [27] Thirdly, carry out the publicity of school affairs. The publicity of school affairs is the edge tool to regulate the power operation of universities. Universities should set up monitoring group of the publicity of school affairs, the main responsibilities of which are to supervise and check whether the publicity of school affairs, party affairs, college affairs and department affairs are put on the work schedule of daily administrative management, whether the contents exposed are true, comprehensive and timely, whether the procedure of publicity is standard, whether concrete measures exposed are implemented, whether the problems reflected by the staff are corrected reasonably and whether reasonable suggestions and opinions put forward by the staff and students are adopted and rectified. Meanwhile, it is necessary to regularly report the situation of supervision and inspection to the leading group of the publicity of school affairs and conduct seminar in terms of the existing problems and take corresponding measures. [28]

\section{E. Supervision Mechanism}

From the perspective of subject elements of power supervision, supervision in universities mainly includes power supervision, surveillance by the masses, supervision by public opinions and social supervision.

1) Power supervision. Using power to supervise power is the most powerful weapon to realize effective supervision: At present, the theoretical circle thinks the power supervision of Chinese universities is in great need of strengthening the following three tasks: Firstly, intensify the consciousness of the main body of power supervision to supervise. All the organizations, power, individual and fields are supervised in universities. [29] Secondly, reform the existing supervision system and strengthen the power supervision. At present, the high power supervision institutions in our country mainly include discipline inspection committee and supervision and auditing departments. But because the discipline inspection committee plays a role under the leadership of Party committee of the same level, this supervisory mechanism will inevitably greatly weaken the supervision strength of the discipline inspection committee. Similarly, although supervision and auditing departments are led by the higher authority of the discipline inspection committee, it belongs to the organization of the same level with the administrative departments supervised. All relations are in the administrative jurisdictional limits of the same level. They are afraid to supervise. The power needs supervision and vice versa. Therefore, it is necessary to reform the existing system that the supervisory organization integrates with the organization supervised and the supervision subject is enslaved to the supervision object and implement the supervision that one power restricts another power and the authority supervision way that guarantees neutrality and independence. For example, implement vertical leadership system with the superior leadership of the discipline inspection committee and the leadership at the same level as supplement. The human, material and financial resources of the discipline inspection commission of universities are solved by the higher authorities and it is directly responsible for the higher authorities. [30] Thirdly, strengthen the self-construction of superintendent office and improve the political and professional quality of cadres, improve working methods and enhance advancement and effectiveness of the supervision and improve the overall level of the supervision. At the meantime, the disciplinary inspection department of universities should also be supervised by the party organization and Party members and cadres, strengthen internal supervision and restraint, resist corruption and make sure to follow the law. [31]

2) Surveillance by the masses: The surveillance by the masses in universities mainly means teachers and students supervise leading cadres. On one hand, strengthen supervision consciousness of teachers and students, enrich channels of supervision of teachers and students and ensure the possibility and universality of the mass participation, guarantee the authority and coerciveness of the system, extensively solicit the opinion of the masses before the publication of decisions and plans, collect opinions and suggestions of the masses through supervisory organizations timely in the process of publication and couple back the comment of correction to the masses after the publication and take the satisfaction degree of the masses as the fundamental criteria to measure the publicity of school affairs. Meanwhile, the monitoring group should often make an inspection tour of the bulletin board of related units and browse their webpage and take the advice of teachers and students. [32] On the other hand, extend the scope of the publicity of school affairs and party affairs and publicize the standard, condition, procedure, realization, and result and complaints method to the society, object of management and service object through effective ways. The disciplinary inspection department shall timely investigate and deal with problems reflected by the staff and consciously transform the supervision without the right of disposal from teachers and students into supervision with the right of disposal. [33]

3) Media supervision. Media is praised as "the fourth power" in western countries: It has unique advantages on supervision. At present, domestic scholars put the research emphasis of media supervision of universities on the new media centering on the internet, especially the microblog. For example, Zhang Jiafei thinks in recent years, the anticorruption on microblog springs up and provides new weapon for network anti-corruption. Universities should also make full use of the microblog to combat corruption. First, depend on the microblog to publicize the work of combating corruption and upholding integrity in universities; second, carry out the ideological guidance of microblog in the construction of combating corruption and upholding integrity in universities; third, improve the system construction of anti-corruption construction of universities; four, scientifically set the flow to 
use microblog to combat corruption in universities. [34] $\mathrm{He}$ Yonggang thinks the policy of new type system that uses microblog to combat corruption and uphold integrity in universities should base on guaranteeing interest subjects of universities under democratic system, moral freedom and authority strengthening and establish new concept of microblog anti-corruption and clearly establish and arrange reasonable and legal system from system, structure, organization and performance in the new field of microblog anti-corruption. First, magnify the long tail effect of microblog and expand the public opinion foundation. Second, promote the legislative norms and build open system of baseline type microblog. Third, clarify the flow of microblog anti-corruption and make it normal. Fourth, establish the idea of microblog and determine the "central position" of microblog anticorruption. Fifth, try university management by professors to build organizational foundation of microblog anti-corruption. Sixth, implement the information disclosure and consolidate the foundation of information source of microblog anticorruption. [35]

4) Social supervision: The construction of modern university system is to establish a multiple mode of cooperation management with macro management of the government, social participation and self-running of school. The construction of anti-corruption and integrity system of universities also needs to promote social cooperation, establish power relations of reasonable counterbalance among the government, universities and the society, from the perspective of overall planning, unceasingly explore the governance structure of the board of directors and absorb social force to participate in the running and management of schools, meanwhile, promote the socialized reform of rear services of universities and the anti-corruption and integrity construction as well. [36]

\section{F. Punishment Mechanism}

Seriously settling corruption cases is an important means to strengthen the work of combating corruption and upholding integrity as well as the inevitable requirement to promote the anti-corruption construction. The theoretical circle widely believes that it is necessary to severely punish personnel in corruption cases of universities, but there are few specific ways of punishment and research achievements. Most of them put forward some abstract principles. For example, Chen Xiaobin thinks strictly execute the punishment system, punish people who violate the law and discipline, violate and break the system to fully embody the rigid design of system and let the system face difficult problems. [37] Niu Ruijie thinks we should consistently insist on the principle of "quality first in auditing and justice first in handling cases". Check erroneous ideas at the outset and warn through dealing with the cases.

\section{CONCLUSION}

In recent years, the research on anti-corruption system of universities conducted by the theoretical circle shows good development momentum. They have put forward penetrating judgments, which provide good reference for the anticorruption and integrity construction of Chinese universities, but they still need to strengthen researches on four aspects.
Firstly, intensify the research and improve the research quality. From the perspective of quantity, there are few existing research achievements on the anti-corruption and integrity system of universities. There are only more than two hundred articles related to the anti-corruption system of universities through searching the CNKI. From the perspective of quality, many research achievements are repeated. There are few innovative theories and opinions. The theoretical circle should intensify the research on anti-corruption and integrity construction of universities, expand the research scope and improve the quality of research achievements. Secondly, strengthen the theoretical research on anti-corruption and integrity system construction of universities. At present, the theoretical circle pays more attention to researching the countermeasures of anti-corruption and integrity problems of universities. The theoretical researches are weak. In face of new tasks and new problems of anti-corruption and integrity construction of universities, they should strengthen theoretical research and form predictive and instructional research results on the theoretical perspective to provide new thoughts for anticorruption and integrity construction of universities. Thirdly, strengthen the research on particularity of anti-corruption and integrity system of universities. Compared with other anticorruption and integrity construction, the anti-corruption and integrity construction in universities has the same aspects as well as special situation. At present, the theoretical circle makes deep analysis on universal problems of anti-corruption system but attaches less importance to special problems of anti-corruption system construction of universities. Fourthly, strengthen the research on experience of anti-corruption system construction of foreign universities. At present, the research results of anti-corruption system mainly embody in Chinese universities. There are few researches on experience of anti-corruption system construction of foreign universities. The theoretical circle should intensify the research on experience of foreign universities in anti-corruption system construction to provide useful references for that of Chinese universities.

\section{REFERENCES}

[1] Ouyang Yuan. Discipline Inspection Commission of Universities Should Play the Role of Organization and Coordination in Building the System of Punishing and Preventing Corruption [J], Research on Discipline Inspection and Supervision Work in Universities, 2008 (1)

[2] Chen Libin. Establishment and Improvement of Punishment and Prevention System of Combating Corruption and Upholding Integrity in Universities [J], Development, 2010 (9)

[3] Li Zhengwu. Establish and Improve Five Mechanisms and Build the System of Punishing and Preventing Corruption with Characteristics of Universities [J], Journal of Chuxiong Normal University, 2006 (7)

[4] Huang Feiyan, etc. Challenges and Countermeasures Faced by the Education of Combating Corruption and Upholding Integrity of Universities in the New Period [J], Journal of Guangzhou University (Social Science Edition), 2012 (4)

[5] Wang Shuqin. Thinking on Supervision Mechanism Construction of Integrity in Universities [J], Journal of Agricultural University of Hebei (Agriculture and Forestry Education Edition), 2008 (1)

[6] Gan Guiyang. Risk Prevention and Control of Integrity of Universities Connotation, Problem and Path $[\mathrm{J}]$, School Party Building and Ideological Education, 2012 (33) 
[7] Chen Xiaobin,etc. Investigation and Countermeasures on Current Situation of Anti-corruption System Construction of Universities in Fujian Province [J], Journal of Fujian University of Technology, 2009 (2)

[8] Gu Zhaoming, etc. Current Situation and Thinking on Anti-corruption System Construction of Universities [J], Theory and Practice of Education, 2009(2)

[9] Jiang Guoying. Brief Discussion on Point, Line and Plane of Anticorruption System Construction of Universities [J], Journal of Yangzhou University (Higher Education Research Edition), 2008(1)

[10] Xiao Zheng. Research on Problems Existing in Anti-corruption System Construction of Universities and Countermeasure [J], Journal of Fujian University of Traditional Chinese Medicine, 2010(6)

[11] Liang Aiwen, etc. Obstacles Existing in Anti-corruption System Construction of Universities and Its Solution [J], Education and Teaching Research, 2011(3)

[12] Tang Zhonghua. Research on Uncorrupt Culture Construction of Universities [D], Master Thesis of Lanzhou University, 2009

[13] Same as [8]

[14] Sun Yinghou. Thinking on Improving Executive Force of Anticorruption System of Universities [J], Journal of Changchun University of Science and Technology, 2012(8)

[15] Hong Niansheng. Research on Intensifying Executive Force of Anticorruption System of Universities [J], Exam Weekly, 2012(66)

[16] Huang Shaobin. Building of Long-term Mechanism of Anti-corruption [J], People's Tribune, 2010(36)

[17] Same as [10]

[18] Niu Ruijie. Building Long-term Mechanism of Combating Corruption and Upholding Integrity of Universities [J], Development, 2007(6)

[19] Lau Zhouhong, etc. Establishment and Improvement of Long-term Mechanism of Anti-corruption Education of Universities [J], Economic Research Guide, 2013(8)

[20] Jiang Xuanxin. Thinking and Exploration on Combating Corruption and Upholding Integrity of Universities [J], Party and Government Forum, 2006(11)

[21] Li Haitao. Countermeasures to Prevent and Control Corruption in Universities [J], Learning Monthly, 2007(18)

[22] Chen Jinming, etc. Research and Analysis on the Formation of Corruption Problems of Universities and Prevention and Control [J], Journal of Southwest Agricultural University (Social Science Edition), 2010(4)

[23] Hong Xingwen, etc. Discussion on Corruption of Universities and Its Correction and Prevention System [J], Higher Education Exploration, 2005(6)

[24] Same as [2]

[25] Same as [14]

[26] Same as [16]

[27] Du Liming. Thinking on Establishment and Improvement of Anticorruption System of Universities [J], Journal of Shanxi Normal University (Social Science Edition), 2002(3)

[28] [32]Wang Hongbin. Use the Publicity of School Affairs to Promote the Anti-corruption Construction of Universities [J], Theory and Practice of Education, 2012(6)

[29] Bai Weichun. Thinking on Improving Leadership System of Corruption Control of Universities [J], Anti-corruption and Integrity Culture Studies, 2011(4)

[30] Same as [23]

[31] Zhao Yunlin. Thinking on Philosophy of the Anti-corruption and Integrity Supervisory Mechanism Construction of Universities [J], Huxiang Forum, 2006(4)

[32] Same as [28]

[33] Hu Shaojun, etc. Influence Factor of Executive Force of Anti-corruption System of Universities and Promotion Strategy [J], Journal of Chifeng University, 2012(9)
[34] Zhang Jiafei. Research on Depending on Microblog to Innovate the Construction of Combating Corruption and Upholding Integrity of Universities [J], Jiannan Literature (Classic Teaching Center), 2012(10)

[35] He Yonggang. Policy Orientation of Building New-type Anti-corruption and Integrity System of Local Universities in the Era of Microblog [J], Journal of Sichuan Administration College, 2012(5)

[36] Shang Guangmei. Research on Anti-corruption and Integrity Construction on the Basis of Modern University System [J], Journal of National Academy of Education Administration, 2012(9).

[37] Same as [7]

[38] Same as [18] 